\title{
Atomic force microscopy analyses on metallic thin films for optical MEMS
}

\author{
Violeta Valentina MERIE ${ }^{1, a^{*}}$, Marius Sorin PUSTAN ${ }^{1, b}$, Gavril NEGREA ${ }^{1, c}$, \\ Corina BîRLEANU ${ }^{1, d}$, \\ ${ }^{1}$ Technical University of Cluj-Napoca, 103-105 Muncii Avenue, 400641, Cluj-Napoca, Romania \\ aVioleta.Merie@stm.utcluj.ro, ${ }^{b}$ pustan@mail.utcluj.ro, ${ }^{c}$ Gavril.Negrea@ispm.utcluj.ro, \\ dcbarleanu@mail.utcluj.ro
}

Keywords: Metallic films, Spectroscopy in point, Work of adhesion, Friction, Nanoindentation.

\begin{abstract}
This paper is a study on three metallic thin films usable for manufacturing optical MEMS. The films were deposited by thermal evaporation on glass substrates. They were characterized from the topographical, tribological and mechanical point of view at nanoscale. The results pointed out that the silver thin films present higher values of the tribological and mechanical properties than the other two films when testing at room temperature. Increasing the testing temperature from 20 to $100{ }^{\circ} \mathrm{C}$ caused a decreased of both hardness and Young's modulus with about 30 up to $55 \%$.
\end{abstract}

\section{Introduction}

The optical microelectromechanical systems (MEMS) are formed in general by multi-layers of metallic thin films characterized by good optical properties. Over the last decades, the attention of the researchers was focused on developing different devices known as microelectromechanical systems (MEMS) that are satisfying the demands of the customers. The properties of the materials employed for manufacturing such devices determine its properties and its performance [1]. The optical MEMS are a category of MEMS devices that are combining the optical, mechanical, and electronic properties in a single device. They are used in the manufacture of optical sensors, attenuators, micro-lenses, micro-mirrors, displays and so on [2-5]. Aluminum [6, 7], gold [8, 9] and silver $[10,11]$ are one of the most used materials for manufacturing optical MEMS due to their physical, chemical, mechanical, and optical properties. These materials can be obtained as thin films by different methods such as thermal evaporation [6], magnetron sputtering [7-9], electron beam deposition [12], and so on.

Arrazat and his colleagues reported their results concerning the evolution of gold thin films deposited by sputtering on silicon substrates. They investigated the deposited films by electron back scatter diffraction analyses that allowed them to study the reliability of micro-switches manufactured using gold thin films [13]. The growth of aluminum thin films and the interfacial precipitation between such films and the silicon substrates were studied by Dutta and his coworkers. They pointed out that at the interface between the aluminum thin films and the silicon substrate during the heat treatment, some silicon precipitates are formed. According to them, these precipitates are supplying the driving force necessary for the deposit of the aluminum thin films [14]. Hojabri and his team worked on determining the influence of substrate temperature on the morphological and structural characteristics of silver thin films deposited by direct current magnetron sputtering on silicon substrates. Their results showed that the substrate temperature

(c) (1) Content from this work may be used under the terms of the Creative Commons Attribution 3.0 license. Any further distribution of this work must maintain attribution to the author(s) and the title of the work, journal citation and DOI. Published under license by Materials Research Forum LLC. 
strongly influence the growth of the silver thin films, their surface roughness, as well as their grain size [15].

This research is an experimental study regarding the deposition and characterization of aluminum, gold, and silver thin films deposited by thermal evaporation on glass substrates, these films being suitable for manufacturing optical MEMS.

\section{Materials and Experimental Procedure}

Aluminum, gold and silver targets with purity of $99.99 \%$ were employed for the deposition of the three metallic films by thermal evaporation. The films were deposited on glass substrate. The substrates were cleaned in high purity alcohol (99.9\%), in an ultrasonic bath in order to remove any possible impurities. Further they were blown with compressed air. We used resistance heated

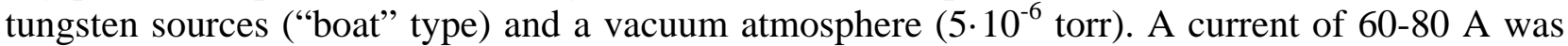
applied. A distance of $50 \mathrm{~mm}$ was kept constant between the substrates and the resistors. The deposited thin films have a thickness of about $70 \mathrm{~nm}$ that was determined using a JEOL JSM 5600 LV scanning electron microscope from the Materials Science and Engineering Department, Technical University of Cluj-Napoca.

The so-obtained thin films were characterized from the topographical, tribological and mechanical point of view at nanoscale. The tests were performed on a XE70 atomic force microscope (AFM) from the Micro and Nano Systems Laboratory, Technical University of ClujNapoca, in a clean environment. An n-type silicon NSC35C cantilever was used for studying the topography and the tribological characteristics of the three metallic thin films. Its characteristics as the manufacturer mentioned - are: length of $130 \mu \mathrm{m}$, thickness of $2 \mu \mathrm{m}$, width of $35 \mu \mathrm{m}$ and force constant of $5.4 \mathrm{~N} / \mathrm{m}$. The set point used during tests was of $10 \mathrm{nN}$. The determination of the adhesion parameters was realized using a PPP-NCHR cantilever by spectroscopy in point. The relative humidity was $31 \%$ and the testing temperature was varied between 20 and $100{ }^{\circ} \mathrm{C}$, increasing it with $20^{\circ} \mathrm{C}$ per testing. As the manufacturer indicated, the characteristics of this cantilever are: tip radius smaller than $10 \mathrm{~nm}$, cantilever thickness of $4 \mu \mathrm{m}$, its width of $30 \mu \mathrm{m}$ and length of $125 \mu \mathrm{m}$, tip height between 10 and $15 \mathrm{~nm}$, force constant of $42 \mathrm{~N} \cdot \mathrm{m}-1$. A TD21464 nanoindentor was employed for determining the mechanical characteristics (hardness and Young's modulus) of the deposited films. The tests were carried out at a relative humidity of $31 \%$ and at different temperatures namely 20, 40, 60, 80 and $100{ }^{\circ} \mathrm{C}$. The characteristics of this nanoindentor - as given by the manufacturer are: cantilever stiffness of $156 \mathrm{~N} / \mathrm{m}$; tip thickness of $19 \mu \mathrm{m}$; tip height of $103 \mu \mathrm{m}$; tip radius smaller than $25 \mathrm{~nm}$ and cantilever length of $581 \mu \mathrm{m}$. The tests were performed at a force limit of $50 \mathrm{nN}$. The obtained curves were interpreted using the XEI Image Processing Tool for SPM (scanning probe microscopy) data by both the Oliver and Pharr (for determining the values of the hardness) and the Hertzian (for determining the values of the Young's modulus) methods [16].

\section{Theoretical formula}

Based on the data obtained for the deflection of the tip when scanning a probe by contact mode, the friction force between the AFM tip and the deposited films was calculated using the equation (1) [17]:

$$
F_{f}=\frac{d_{z} \cdot r \cdot G \cdot h^{3} \cdot b}{l^{2} \cdot s}
$$


where $F_{f}$ represents the friction force between the tip and the tested films, $\mathrm{dz}$ is the deflection of the tip, $r$ is a constant ( $r=0.33$ ), $G$ is the shear modulus (for silicon: $G=50.92 \cdot 10^{-3} \mathrm{~N} \cdot \mu \mathrm{m}^{-2}$ [18]), $\mathrm{s}$ is tip height $(\mathrm{s}=15 \mu \mathrm{m})$ while $\mathrm{h}, \mathrm{b}$ and 1 are the dimensions of the cantilever that are specified in the previous section.

The data obtained from the spectroscopy in point tests allowed us to determine the work of adhesion, $\mathrm{W}_{\mathrm{a}}$, using the following formula [17]:

$W_{a}=F_{a d h} \cdot(c \cdot \pi \cdot R)^{-1}$

where $F_{\text {adh }}$ represents the adhesion force between the AFM tip and the investigated thin films, $c$ is a constant and $\mathrm{R}$ is tip radius. There are two models that help us to calculate the work of adhesion namely the JKR (Johnson-Kendall-Roberts) and the DMT (Derjaguin-Müller-Toporov) models respectively. The difference between these two models is given by the value of the "c" constant. Thus, the JKR model considers that $\mathrm{c}=1.5$ while the DMT model considers that $\mathrm{c}=2$ [19]. The tip used for testing the deposited titanium nitride films has a radius of $10 \mathrm{~nm}$.

\section{Results and Discussions}

Once the films were deposited, they were characterized from topographical, adhesion, tribological and mechanical point of view, these characteristics being very important in the operating of an optical MEMS device. The average roughness, friction force, adhesion force, work of adhesion, hardness and Young's modulus were determined, and we pointed out the influence of testing temperature on the adhesion and mechanical properties.

\section{Topography and adhesion}

The values of the topography parameter were determined to validate what we have found out from the $3 \mathrm{D}$ images. The values of the $\mathrm{R}_{\mathrm{a}}$ (average roughness), $\mathrm{R}_{\mathrm{q}}$ (room mean square roughness), $\mathrm{R}_{\mathrm{sk}}$ (skewness roughness) and $R_{k u}$ (kurtosis roughness) are given in Table 1 . The average values determined for aluminum, gold and silver thin films were about $5.7 \mathrm{~nm}, 2.7 \mathrm{~nm}$, and $4.8 \mathrm{~nm}$ respectively.

Table 1. Topographical parameters of the deposited thin films

\begin{tabular}{ccccc}
\hline Material & $\mathrm{R}_{\mathrm{a}}(\mathrm{nm})$ & $\mathrm{R}_{\mathrm{q}}(\mathrm{nm})$ & $\mathrm{R}_{\mathrm{sk}}(-)$ & $\mathrm{R}_{\mathrm{ku}}(-)$ \\
\hline Aluminum & 5.68 & 7.14 & -0.381 & 2.948 \\
Gold & 2.68 & 3.47 & -0.477 & 4.031 \\
Silver & 4.83 & 5.55 & 0.001 & 1.882 \\
\hline
\end{tabular}

Adhesion is considered to be the major failure mechanism that affects the reliability of a MEMS device. In this regard, the adhesion force between each deposited thin film and the AFM tip was determined by spectroscopy in point. At room temperature, the smallest adhesion was marked out on the aluminum thin films $(78.4 \mathrm{nN})$, while the highest is specific to the silver thin films $(304.4 \mathrm{nN})$. We also studied the fluctuation of the adhesion force in terms of testing temperature. This fluctuation is graphically given in Fig. 1. In general, an exponential increase of the adhesion parameter with the increase of temperature from 20 to $100{ }^{\circ} \mathrm{C}$ can be observed. The most significant increase in adhesion force is specific to the gold thin films where the adhesion 
force increases from $110.2 \mathrm{nN}$ (at $20^{\circ} \mathrm{C}$ ) to $991 \mathrm{nN}$ (at $100{ }^{\circ} \mathrm{C}$ ). The work of adhesion was calculated based on the average values that we've determined for the adhesion force. This characteristic was calculated using the two models: DMT and JKR (see section 3). The fluctuation of the work of adhesion is given in Fig. 2. In both cases, the silver thin films present the highest value of this property (9.69 J $\cdot \mathrm{m}^{-2}$ for the DMT model and $12.93 \mathrm{~J} \cdot \mathrm{m}^{-2}$ for the JKR model). Instead the aluminum thin films are characterized by the smallest work of adhesion (2.5 for the DMT model and $3.33 \mathrm{~J} \cdot \mathrm{m}^{-2}$ for the JKR model). The values for the work of adhesion of gold thin films are slightly higher (about 0.7 times) than those specific to the aluminum thin films. These results are in accordance with the results that we've obtained for the friction force of these metallic thin film. Further research will aim at determining the experimental values for this parameter and to compare them to the theoretical values that are presented in this study.

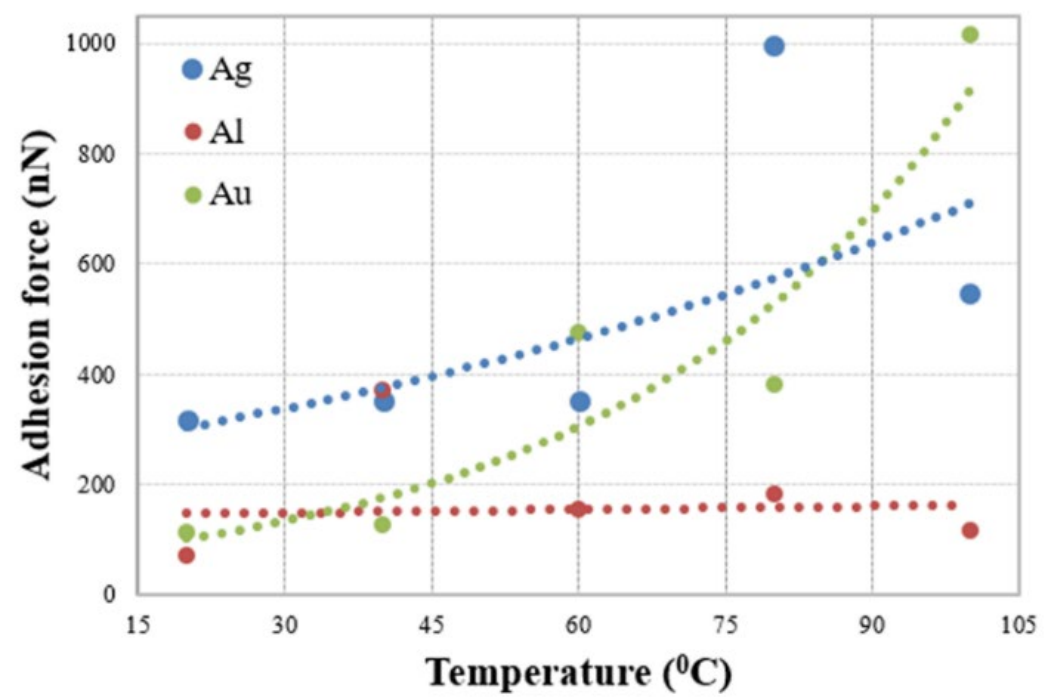

Fig. 1. Temperature influence on the adhesion force of the deposited aluminum, gold and silver thin films.

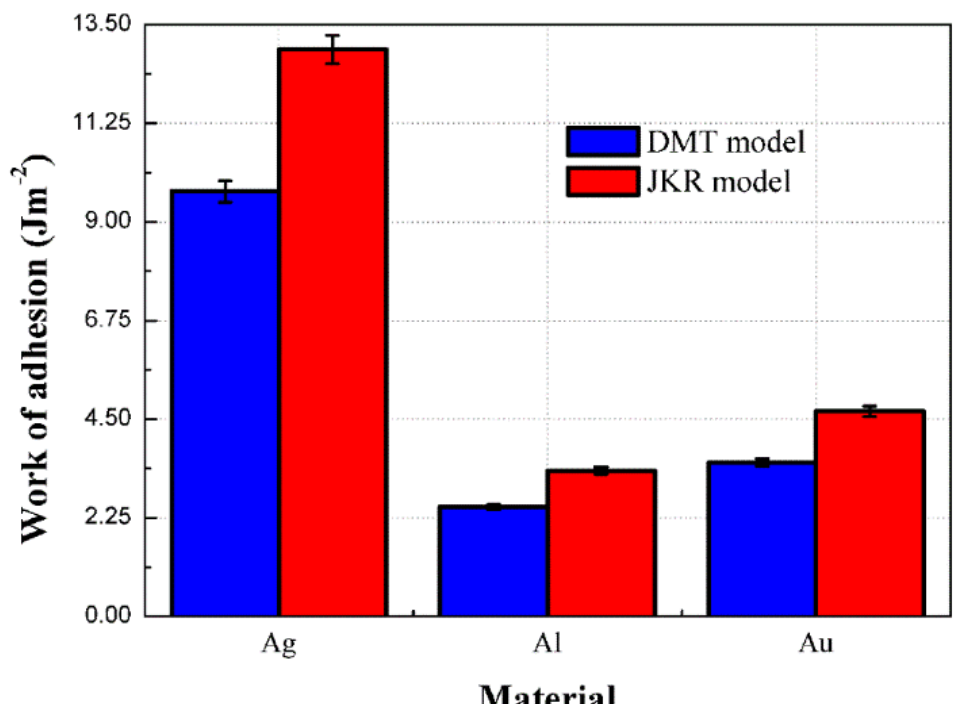

Fig. 2. Work of adhesion of the deposited aluminum, gold and silver thin film determined using the DMT and JKR models. 


\section{Tribological characterization}

The tribological characterization implied the determination of the friction force between the AFM tip and the surface of the deposited thin films.

The change in this friction force at room temperature is graphically given in Fig. 3. The average value if the friction parameter for the aluminum, gold and silver thin films is $0.87,3.80$ and 8.60 $\mathrm{nN}$ respectively. The fluctuation of friction force is, in general, of $5 \%$ for each film. We must highlight that the friction force is strongly influence, at nanoscale, by the adhesion force. This claim confirms our previous results regarding the adhesion force of the three metallic films.

The friction force is strongly influenced at nanoscale by the adhesion force that occurs between the sample and the AFM tip. Besides the friction coefficient, this friction parameter is also directly proportional to the sum between the loading charge and the adhesion force.

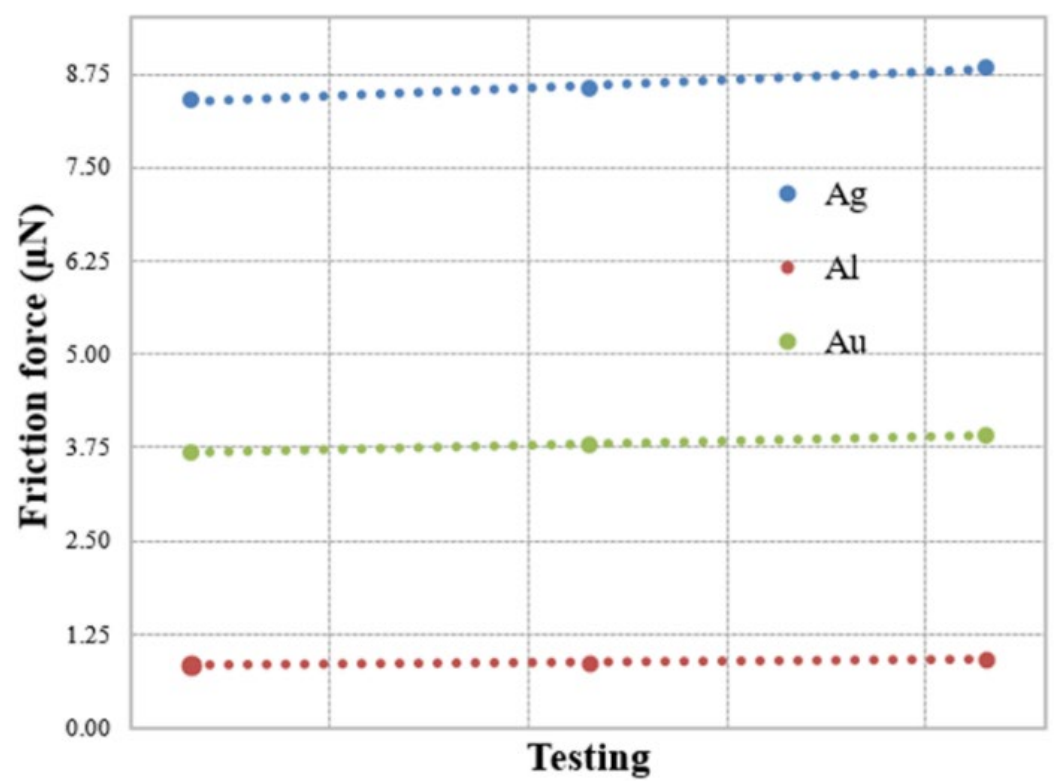

Fig. 3. The friction force between the AFM tip and the deposited aluminum, gold and silver thin films.

\section{Mechanical characterization}

The hardness and the Young's modulus were determined for each film to characterize them from the mechanical point of view. The determination of the hardness was realized using the Hertzian model while the force vs. Z scan curves were interpreted using the Oliver and Pharr model for determining the Young's modulus. The difference between these two models is that the Hertzian model assumes there is no plastic deformation after the nanoindentation of the sample. Instead, the other model assumes that the sample undergoes both plastic and elastic deformations.

This fluctuation of hardness according to the testing temperature is given in Fig. 4. As can be seen, the silver films are characterized by the highest hardness not only at room temperature (6.72 GPa) but also at 20, 40,60, 80 and $100^{\circ} \mathrm{C}$. Although it must be pointed out that the variation in this mechanical parameter is more pronounced for the same silver films when the hardness varied from $6.72 \mathrm{GPa}$ at $20{ }^{\circ} \mathrm{C}$ to $3.63 \mathrm{GPa}$ at $100{ }^{\circ} \mathrm{C}$. In particular, the values of the hardness at nanoscale for the aluminum and gold thin films are relatively closed especially when testing at 60 ${ }^{\circ} \mathrm{C}$. The gold thin films are characterized by the best stability of this mechanical property, its values varying between $1.43 \mathrm{GPa}$ at room temperature to $0.99 \mathrm{GPa}$ at $100{ }^{\circ} \mathrm{C}$. 
The fluctuation of Young's modulus is presented in Fig. 5. At room temperature, the aluminum, gold, and silver thin films were determined to have a Young's modulus of 21.4, 44.3, and 52.03 GPa respectively. Concerning the change in this property with the increase in temperature, the silver thin films presented a gradually decrease from 52.03 to $36.26 \mathrm{GPa}$. Conversely, the aluminum and gold thin films show between 40 and $60{ }^{\circ} \mathrm{C}$ a relative conservation of the elasticity followed by a drop in this mechanical property.

The obtained values for the mechanical characteristics of thin films determined at nano scale are smaller than the reported values for the bulk materials. This trend was also marked out by Chang-Wook Baek and his co-workers [20]. The determined values are in good agreement with the values reported in the scientific literature [12, 13, 21-23].

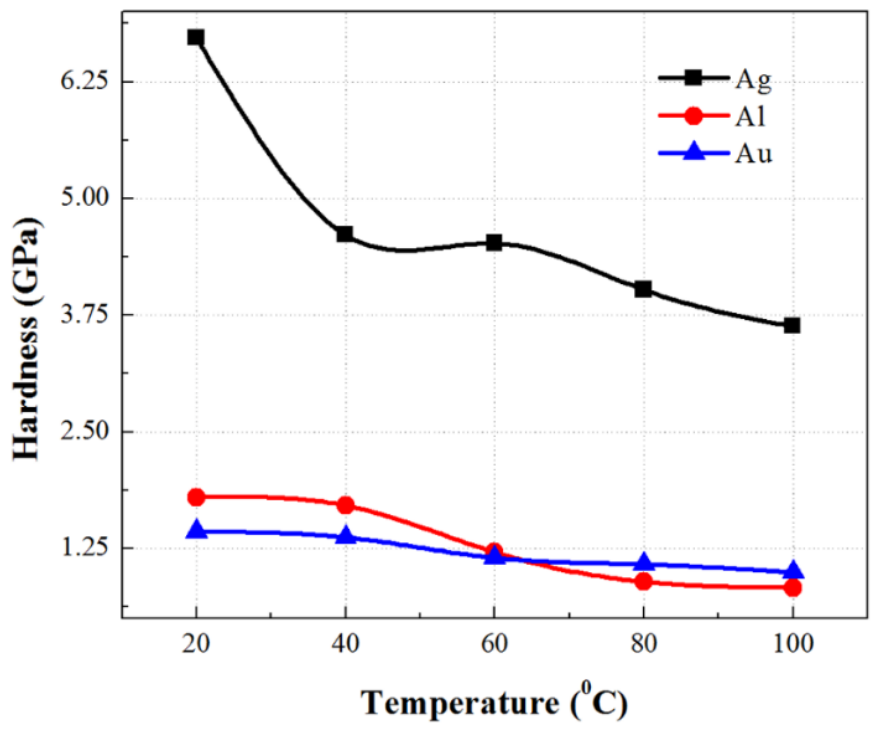

Fig. 4. Temperature influence on the hardness of the deposited aluminum, gold and silver thin films.

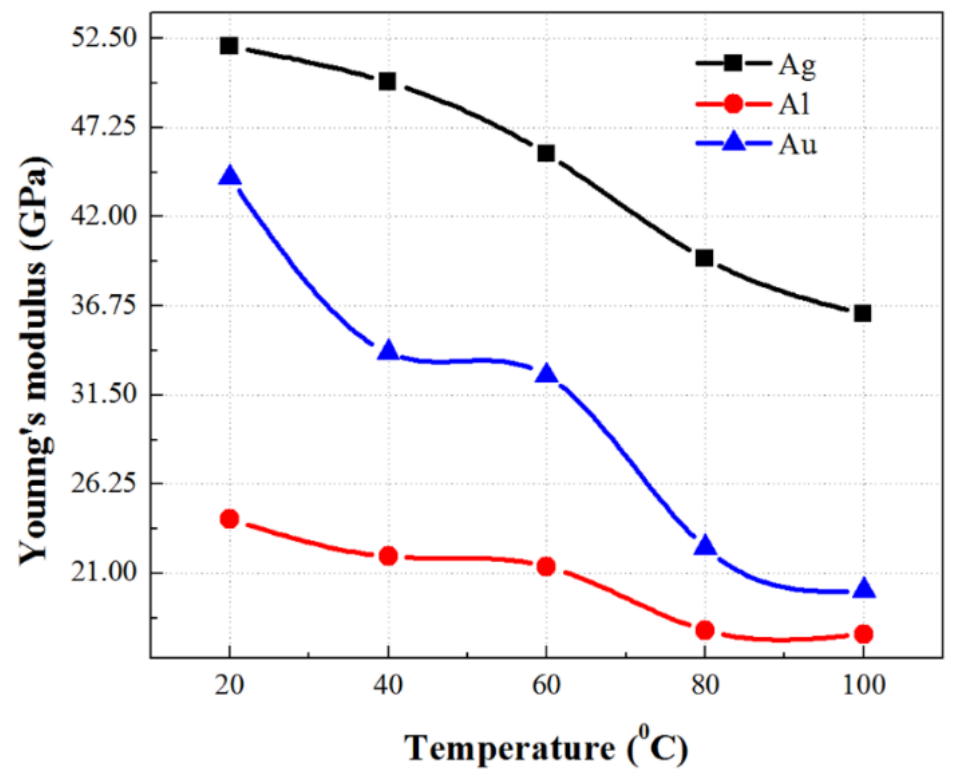

Fig. 5. Temperature influence on the Young's modulus of the deposited aluminum, gold and silver thin films. 


\section{Conclusions}

Aluminum, gold, and silver thin films were deposited by thermal evaporation on glass substrates. The deposited films were characterized by the topographical, tribological, adhesion and mechanical point of view at nanoscale. The gold thin films are characterized by the smallest value of average roughness $(2.68 \mathrm{~nm})$ while the highest value of this parameter $(5.68 \mathrm{~nm})$ was determined for the aluminum thin films. The increase of the testing temperature caused an increase of the adhesion force about 3.2 times for silver, 4.5 times for aluminum and 9 times for gold. The smallest and the highest work of adhesion was calculated for the aluminum thin films (2.5 to 3.33 $\mathrm{J} \cdot \mathrm{m}-2)$ and silver thin films (9.69 to $12.93 \mathrm{~J} \cdot \mathrm{m}^{-2}$ ) respectively. The friction force between the deposited thin films and the AFM tip varied between 0.87 (aluminum) and $8.60 \mu \mathrm{N}$ (silver). The silver thin films present the highest values for both the Young's modulus (52 GPa) and hardness $(6.72 \mathrm{GPa})$ at room temperature. Increasing the testing temperature from 20 to $100{ }^{\circ} \mathrm{C}$ caused a decrease of the two mechanical characteristics but the decrease was more pronounced for the aluminum thin films (hardness) and gold thin films (Young's modulus).

\section{Acknowledgement}

This work was supported by a grant of the Romanian National Authority for Scientific Research and Innovation, CNCS-UEFISCDI, project number PN-II-RU-TE-2014-4-1271

\section{References}

[1] S.M. Han, R. Saha, W.D. Nix, Determining hardness of thin films in elastically mismatched film-on-substrate systems using nanoindentation, Acta Mater. 54 (2006) 1571-1581. https://doi.org/10.1016/j.actamat.2005.11.026

[2] C.L. Linslal, P.M. Syam Mohan, A. Halder, T.K. Gangopadhyay, Analysis and modeling of an optical fiber loop resonator and an evanescent field absorption sensor for the application for

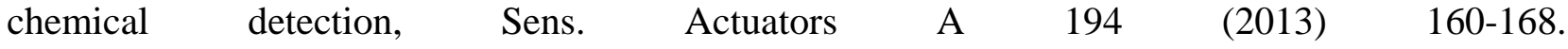
https://doi.org/10.1016/j.sna.2013.01.021

[3] E.M. Bourim, H.-Y. Kim, J.-S. Yang, J.-W. Yang, K.-S. Woo, J.-H. Song, S.-K. Yun, Creep behavior of undoped and La-Nb codoped PZT based micro-piezoactuators for micro-optical modulator applications, Sens. Actuators A 155 (2009) 290-298. https://doi.org/10.1016/j.sna.2009.08.020

[4] W. Hortschitz, H. Steiner, M. Sachse, F. Kohl, J. Schalko, F. Keplinger, Hybrid optical MEMS vibration sensor, Procedia Eng. 5 (2010) 420-423. https://doi.org/10.1016/j.proeng.2010.09.136

[5] C. Winter, L. Fabre, F. Lo Conte, L. Kilcher, F. Kechana, N. Abelé, M. Kayal, Micro-beamer based on MEMS micro-mirrors and laser light source, Procedia Chem. 1 (2009) 1311-1314. https://doi.org/10.1016/j.proche.2009.07.327

[6] N. Barbosa, R.R. Keller, D.T. Read, R.H. Geiss, R.P. Vinci, Comparison of electrical and microtensile evaluations of mechanical properties of an aluminum film, Metall. Mater. Trans. A 38A (2007) 2160-2167. https://doi.org/10.1007/s11661-007-9112-y

[7] J. Martinez-Quijada, S. Caverhill-Godkewitsch, M. Reynolds, L. Gutierrez-Rivera, R.W. Johnstone, D.G. Elliott, D. Sameoto, C.J. Backhouse, Fabrication and characterization of aluminum thin film heaters and temperature sensors on a photopolymer for lab-on-chip systems, Sens. Actuators A 193 (2013) 170-181. https://doi.org/10.1016/j.sna.2013.01.035 
[8] O. Okman, J. W. Kysar, Fabrication of crack-free blanket nanoporous gold thin films by galvanostatic dealloying, J. Alloys Compd. 509 (2011) 6374-6381. https://doi.org/10.1016/j.jallcom.2011.02.115

[9] V. Raffa, B. Mazzolai, A. Mondini, V. Mattoli, A. Menciassi, P. Dario, Investigation on a sensitive $\mathrm{Au}$ thin film deposited on different substrates: Physical analysis via FIB and chemical analysis via evaluation of Au sensitivity to Hg0, Sens. Actuators B 122 (2007) 475-483. https://doi.org/10.1016/j.snb.2006.06.013

[10] Y. Nakanishi, K. Kato, H. Omoto, T. Tomioka, Improvement in salt-water durability of Ag thin films deposited by magnetron sputtering using argon and nitrogen mixed gas, Vac.87 (2013) 232-236. https://doi.org/10.1016/j.vacuum.2012.02.053

[11] I.C. Estrada-Raygoza, M. Sotelo-Lerma, R. Ramírez-Bon, Structural and morphological characterization of chemically deposited silver films, J. Phys. Chem. Solids 67 (2006) 782-788. https://doi.org/10.1016/j.jpcs.2005.10.183

[12] Y. Cao, S. Allameh, D. Nankivil, S. Sethiaraj, T. Otiti, W. Soboyejo, Nanoindentation measurements of the mechanical properties of polycrystalline Au and Ag thin films on silicon substrates: Effects of grain size and film thickness, Mater. Sci. Eng. A 427 (2006) 232-240. https://doi.org/10.1016/j.msea.2006.04.080

[13] B. Arrazat, V. Mandrillon, K. Inal, M. Vincent, C. Poulain, Microstructure evolution of gold thin films under spherical indentation for micro switch contact applications, J. Mater. Sci. 46 (2011) 6111-6117. https://doi.org/10.1007/s10853-011-5575-8

[14] I. Dutta, M. Burkhard, S. Kuwano, T. Fujita, M.W. Chen, Correlation between surface whisker growth and interfacial precipitation in aluminum thin films on silicon substrates, J. Mater. Sci. 45 (2010) 3367-3374. https://doi.org/10.1007/s10853-010-4359-x

[15] A. Hojabri, Z. Kavyani, M. Ghoranneviss, Effect of substrate temperatures on structural and morphological properties of nano-crystalline silver thin films grown on silicon substrates, J. Inorg. Organomet. Polym. Mater. 27 (2017) 53-60. https://doi.org/10.1007/s10904-016-0443-2

[16] W.C. Oliver, G.M. Pharr, An improved technique for determining hardness and elastic modulus using load and displacement sensing indentation experiments, J. Mater. Res.7 (1992) 1564-1583. https://doi.org/10.1557/JMR.1992.1564

[17] V. Merie, M. Pustan, G. Negrea, C. Birleanu, Research on titanium nitride thin films deposited by reactive magnetron sputtering for MEMS applications, Appl. Surf. Sci. 358 (2015) 525-532. https://doi.org/10.1016/j.apsusc.2015.07.063

[18] M.A. Hopcroft, W.D. Nix, T.K. Kenny, What is the Young's modulus of silicon?, J. Microelectromech. Syst. 19 (2010) 229-238. https://doi.org/10.1109/JMEMS.2009.2039697

[19] J. Drelich, Adhesion forces measured between particles and substrates with nano-roughness, Miner. Metall. Process. 23 (2006) 226-232.

[20] C.-W. Baek, Y.-K. Kim, Y. Ahn, Y.-H. Kim, Measurement of the mechanical properties of electroplated gold thin films using micromachined beams structures, Sens. Actuators A 117 (2005) 17-27. https://doi.org/10.1016/j.sna.2003.11.041

[21] H.D. Esponisa, B.C. Prorok, Size effects on the mechanical behavior of gold thin films, J. Mater. Sci. 38 (2003) 4125-4128. https://doi.org/10.1023/A:1026321404286 
[22] P. Peng, G. Liao, T. Shi, Z. Tang, Y. Gao, Molecular dynamic simulations of nanoindentation in aluminum thin film on silicon substrate, Appl. Surf. Sci. 256 (2010) 6284-6290. https://doi.org/10.1016/j.apsusc.2010.04.005

[23] S.W. Han, H.W. Lee, H.J. Lee, J.Y. Kim, J.H. Kim, C.S. Oh, S.H. Choa, Mechanical properties of $\mathrm{Au}$ thin film for application in MEMS/NENS using microtensile test. Curr. Appl. Phys. 6S1 (2006) e81-e85. 